\title{
USING MULTIPLE CRITERIA DECISION ANALYSIS (MCDA) TO ASSIST IN ESTIMATING RESIDENTIAL HOUSING VALUES
}

\author{
Fernando A. F. FERREIRA a,b,*, Ronald W. SPAHR ${ }^{\text {b }}$, Mark A. SUNDERMAN b \\ a ISCTE Business School, BRU-IUL, University Institute of Lisbon, Avenida das Forças Armadas, \\ 1649-026 Lisbon, Portugal \\ ${ }^{b}$ Fogelman College of Business and Economics, University of Memphis, Memphis, TN 38152-3120, USA
}

Received 24 February 2015; accepted 27 July 2015

\begin{abstract}
Considerable literature exists regarding the complexity of the residential real estate appraisal process and the methods employed to determine initial listing prices as estimates of intrinsic market prices. Deviations in residential real estate intrinsic values occur due to a multiplicity of attributes and explanatory factors requiring consideration. We conduct a panel study using a Multiple Criteria Decision Analysis (MCDA) based framework that utilizes the skills and knowledge of a panel of residential real estate professionals (i.e. appraisers and realtors). We demonstrate how cognitive mapping and the Measuring Attractiveness by a Categorical Based Evaluation Technique (MACBETH) may assist in estimating appropriate offer/sale prices and strengthening current valuation approaches such as using comparables and/or hedonic modeling. The managerial implications of our MCDA-based framework and some avenues for future research are also presented.
\end{abstract}

KEYWORDS: Decision support; Housing valuation; MCDA; Residential real estate

\section{INTRODUCTON}

Accurately estimating the initial asking/sale price for residential real estate is one of the essential first steps in facilitating realtors and sellers successes in their goal of finding a buyer. Traditionally, the estimation of the appropriate initial asking price, from which the final sale price is negotiated, has been the responsibility of realtors and appraisers. In many cases, even before appraisers are asked to determine value, real estate brokers and sales associates are asked to establish initial listing prices. Thus, it is critical that these real estate professionals understand existing residential housing market conditions and the attributes that determine individual parcel values. The establishment of a fair listing price is important in facilitating a timely and mutually beneficial sale.

Much has been written about the appraisal process and the methods employed in the establishment of residential real estate initial listing prices. Nonetheless, market value estimation for residen-

\footnotetext{
* Corresponding author. E-mail: fernando.alberto.ferreira@iscte.pt; fernando.ferreira@memphis.edu
}

tial real estate remains a complex undertaking (Englund et al. 1998; Fischer 2003). Residential real estate intrinsic values deviate due to a variety of factors that require consideration in the evaluation process. Thus, despite considerable progress to date, each valuation approach has specific limitations requiring further clarification of selected criteria and trade-off calculations (Ferreira et al. 2012). Using cognitive maps and multiple criteria decision analysis (MCDA), to address valuation limitations, may prove effective by incorporating multiple perceptions and decision makers into a framework for residential real estate valuation.

Methodologically, our MCDA-based framework uses cognitive maps and measures attractiveness to determine an initial offer/ask price for residential real estate by applying a categorical-based evaluation technique (MACBETH) (Bana e Costa, Vansnick 1994; Bana e Costa et al. 2012). MCDA may reinforce current valuation approaches such as the use of comparable properties or hedonic modeling valuation approaches, by potentially reducing omitted criteria and promoting better un- 
derstanding of the cause-and-effect relationships among attributes (Eden 2004; Filipe et al. 2015). Also, MACBETH may improve value estimation of unique attributes and evaluation criteria (Ferreira et al. 2011a, 2015). In addition, by integrating cognitive mapping and MACBETH, our valuation approach may result in initial asking prices satisfactory to both sellers and agents, yet also attractive to potential buyers. We find no prior literature applying this approach, thus we are confident that our study adds to the residential real estate valuation literature.

The remainder of the paper is structured as follows. The ensuing section provides a review of the literature on real estate pricing models and strategies. Section 3 describes the decision support system designed. The last section discusses the major advantages and limitations of our evaluation system, presents concluding remarks and some avenues for future research.

\section{BACKGROUND ON REAL ESTATE PRICING ESTIMATION}

Indicative of much of the residential real estate literature, Bin (2004: 68) states that "accurate price prediction of housing sales price is important in the operation of the housing market". Accurate estimates of sales prices are important not only for sellers and buyers, but also for financial institutions managing underwriting risk related to housing finance. Nevertheless, the estimation of market value for residential real estate is a relatively complex endeavor, because residential housing usually contains unique packages of attributes that are potentially conflicting and interfering with market value predictions (for further developments, see Clark 1995; González, Formoso 1995; Wolverton, Gallimore 1999; Balarine 2004; Hongyu, Yue 2005; Yan et al. 2007; Malienè et al. 2010; Zhou, Haurin 2010; Benefield et al. 2011; Cheng et al. 2011; Ettema 2011).

Also discussed in the literature are several techniques for estimating sales prices such as hedonic modeling, repeated-sales methods and "hybrid" techniques combining both (e.g. Quigley 1995; Englund et al. 1998; Bin 2004; Smith 2006; Guo et al. 2007; Gouriéroux, Laferrère 2009; Hjalmarsson, E., Hjalmarsson R. 2009; Dorsey et al. 2010; Pace et al. 2000; Schulz, Werwatz 2011; Wu et al. 2011). Hedonic modeling is, perhaps, the most widely used mass appraisal technique in estimating residential real estate market values (cf. Bou- rassa et al. 2010; Osland 2010), where the price is defined by a set of lot and housing attributes such as size, number of rooms, geographic location and age of the house, to name just a few. As noted by Gouriéroux and Laferrère (2009: 206), "the hedonic approach assumes a pricing model where a dwelling is represented by a limited number of observed characteristics, each with their own prices".

Applying hedonic modeling to real estate valuation including flexible functional forms, nonparametric or semi-parametric regressions and/ or spatial models that capture correlations within submarkets allowing for temporal asymmetry, may have some limitations and has been criticized. Criticism generally has been: (1) offers limited guidance regarding the relationship among housing prices and attributes, with "potentially serious consequences of functional misspecification" (Bin 2004: 69); (2) being limited by a lack of data on property attributes (according to Dorsey et al. (2010: 91), “[...] hedonic indexes can potentially overcome the limitations of the median price and repeat-sales indexes but are seldom constructed because of a lack of data"); (3) depending not only on previously observed and recorded characteristics of properties but also on previously observed and recorded prices (Quigley 2006; Gouriéroux, Laferrère 2009); (4) estimating coefficients that may suffer from omitted variable bias (Hjalmarsson, E.; Hjalmarsson R. 2009); and (5) "not depending on the demand for housing in the market, but only on characteristics of the dwelling and its environment" (Ettema 2011: 1) (for further discussion, see also Peterson, Flanagan 2009; Shin et al. 2011).

While significant progress has occurred, we observe that current methodological approaches, including hedonic modeling, are not without limitations in terms of evaluation criteria selection and trade-off calculations. As emphasized by Bourassa et al. (2010: 139), "caution, however, should be exercised [...]. Appropriate variables must be selected carefully and measured accurately". From this perspective, MCDA techniques may provide a useful contribution in overcoming the limitations identified above. In particular, the integration of cognitive maps and MACBETH (background details are presented in section 3) can inform and support the development of more realistic price estimation systems. First, cognitive mapping may assist in reducing the number of omitted criteria and promoting a better understanding of the cause-and-effect relationships among evaluation criteria/attributes (Eden 2004; Filipe et al. 2015). 
Second, MACBETH tends to improve the process of estimating compensations among those same evaluation criteria (Ferreira et al. 2014a).

Another important feature of MCDA is that it is designed as a synergistic methodology that may be used to assist price estimation by allowing decision makers/real estate professionals to periodically monitor price updates. However, it is worth noting that "the hedonic approach assumes a pricing model that explains how the price of an apartment or house depends on its characteristics" (Gouriéroux, Laferrère 2009: 209). MCDA may be used in a complementary rather than a substitution role in establishing initial offering prices, based not only on housing attributes (or characteristics) but also on the semantic judgments and professional experience of real estate professionals. As already noted by Suedel et al. (2009: 5), "criteria such as human impacts [...] and social preferences should also be added because these criteria also can significantly affect the [...] decision and are important to stakeholders".

The MCDA framework facilitates integration of uncertainty and allows for non-optimal solutions (Ferreira et al. 2011b) by accepting inputs from active/professional decision makers, thus reducing data requirements (one of the major limitations of traditional hedonic models). In this sense, and because of the professional experience, practical skills and realism brought by the decision makers, "applying multiple criteria analysis methods may increase the efficiency of modeling and forecasting of real estate sector and its macro- and micro-level environment and its development trends" (Zavadskas et al. 2005: 136).

\section{A "NEW" SYSTEM FOR RESIDENTIAL HOUSING SALE ESTIMATION}

As previously mentioned, we believe that the integration of cognitive maps and MACBETH is a new and novel approach as an addition to the real estate valuation literature. This approach is a proven and effective technique improving criteria selection transparency, trade-off calculations and group decision making for a number of different applications (e.g. Belton, Stewart 2002; Bana e Costa et al. 2005; Ferreira et al. 2012, 2014b; Filipe et al. 2015). MCDA, as applied to real estate valuation, may improve price estimation accuracy.

Because of their versatility and interactivity, cognitive maps have been adopted as important tools in the structuring and clarification of a num- ber of complex problems. Ackermann and Eden (2001), Eden and Banville (2003), Ferreira et al. (2012, 2015) and Filipe et al. (2015), among others, find that maps are particularly useful to: (1) promote discussion with and/or among decision makers, (2) reduce the number of omitted variables in a decision making framework; and (3) increase understanding of the cause-and-effect relationships among criteria.

MACBETH is an interactive approach based on pairwise comparisons, which are easy to make, discuss, justify and agree on (cf. Dyer, Forman 1992). According to Bana e Costa and Vansnick (1994) and Bana e Costa et al. (2012), the technical procedure proposed by the MACBETH approach supports the construction of numerical scales grounded on semantic judgments, which seems to be useful in dealing with trade-offs in a real estate price estimation context, where most of the variables under consideration are intrinsically qualitative (technical details are presented in subsection 3.2).

Our study involved three main parts: (1) structuring, where cognitive mapping techniques are used to obtain residential housing valuation criteria; (2) evaluation, where the MACBETH technique is applied to calculate trade-offs not only among valuation criteria but also among impact levels in each criterion; and (3) recommendations, which explores the methodological approach proposed as means of adding value to existing methods regarding residential housing sale price estimation. Advantages and limitations of our framework are also discussed. We accomplished these three phases with four intensive work sessions with an average duration of five hours each.

\subsection{The structuring part}

The structuring phase of our real estate valuation problem was developed in our first two work sessions. Several issues were addressed during these work sessions, namely: design of a collective cognitive map and definition of an evaluation tree with respective descriptors and impact levels.

\subsubsection{Participants}

Decision makers play an important role in the MCDA framework because their active participation is required to assist the facilitator/researcher in designing, implementing and developing the evaluation framework. From this premise, the composition of a panel of experts in real estate was carefully addressed in our study, which faced two major initial constrains: (1) limited availability of real estate experts to participate in group meet- 
ings; and, in sequence, (2) difficulties in getting the entire panel together. Given these constrains, we convened a panel of seven experts composed of four realtors and three appraisers, who operate in Memphis, TN. It should be pointed out that the different backgrounds of the panel members allowed us to collect and confront different opinions and orientations in terms of current markets and current practices of residential housing price estimation (for further details on the importance of appraisal-based information, see Downs, Güner 2012 , 2013). One of the two facilitators who conducted the group meetings was also responsible for recording and registering the outcomes achieved in each group session.

\subsubsection{Problem formulation}

This study integrates cognitive maps and MACBETH to develop a decision support system for residential housing valuation/price estimation. The problem consists of identifying and interrelating different valuation criteria/property attributes considered important to: (1) better value estimates of residential housing; (2) allow for comparisons among home sales; and (3) monitor prices over the time. Rankings will be presented but they are not the major aim/concern of our valuation system.

\subsubsection{The SODA approach and the collective cognitive map}

To begin the operational phase and obtain valuation criteria/property attributes, we defined the following trigger question: "Grounded on your values and professional experience, what are the main characteristics and/or factors of a house that most influence its sale price?" This question provided the focus for discussion. It is worth noting that in this study only single-family residential real estate was addressed; although our framework may be applied to the valuation of apartments, condominium and/or other types of property valuation. Single family homes were selected to focus on only one category of real estate, reduce ambiguity and guarantee better decision-making results.

For convenience, and given the constraints presented in subsection 3.1.1, we decided to start the structuring part of our study following SODA II a variant of the strategic options development and analysis (SODA) methodological approach (Eden, Ackermann 2001a, 2001b). More specifically, the first group session was initiated with careful explanations of basic concepts related to cognitive mapping and the "post-its technique". This initial procedure is very important to avoid misunder- standings between the facilitators and the panel members. From the practical point of view, it was explained that the "post-its" technique consists of writing what each real estate expert consideres as a relevant criterion on a post-it and stick that post-it on a table/board (or on white wall sheets in our case). The process was repeated until the decision makers demonstrated satisfaction with the number and depth of criteria revealed (for further details, see Ackermann, Eden 2001; Ferreira et al. 2011a). Following this initial "brain storming" technical procedure, the post-its were subsequently organized by clusters (also known as areas of concern), allowing additional discussion on their significance. As reported by Malienè (2011: 444), "comprehensive description of the criteria ensures the maximum precision in estimating price of property". This procedural step was concluded only with the participants' agreement on the form and content of the "strategic map" (as it is called in the literature). The final version of the map, which was developed using the Decision Explorer software, is presented in Figure 1.

Considering the size of the final version of the strategic map, which aggregates more than 300 criteria, Figure 1 is merely illustrative. Nevertheless, it should be recalled that the final version is a result of the discussion/negotiation established among the panel members, and represents the group's agreement. As can be observed, the final version of the map depends on multiple factors, namely: circumstances, facilitator's experience and/or skills, decision makers involved, sessions' duration, etc. Although this might be seen as a shortcoming of our framework, it should be highlighted, on the other hand, that due to the decision makers' direct involvement and the amount of information discussed, the use of cognitive mapping has proved valuable to structure the issue at hand and improve understanding regarding housing sale estimation. From this premise, cognitive mapping should be seen as an instrument to provide consolidated information based on opinions of a certain group of experts. Furthermore, the approach is process-oriented, allowing for adjustment possibilities.

\subsubsection{Descriptors and impact levels}

Based on the final version of the map, and considering Keeney's (1992) guidelines, a second group session took place to identify key evaluation criteria (also known as fundamental points of view (FPVs); from now on represented by $\mathrm{FPV}_{\mathrm{n}}$, with $n$ representing the number of the respective 


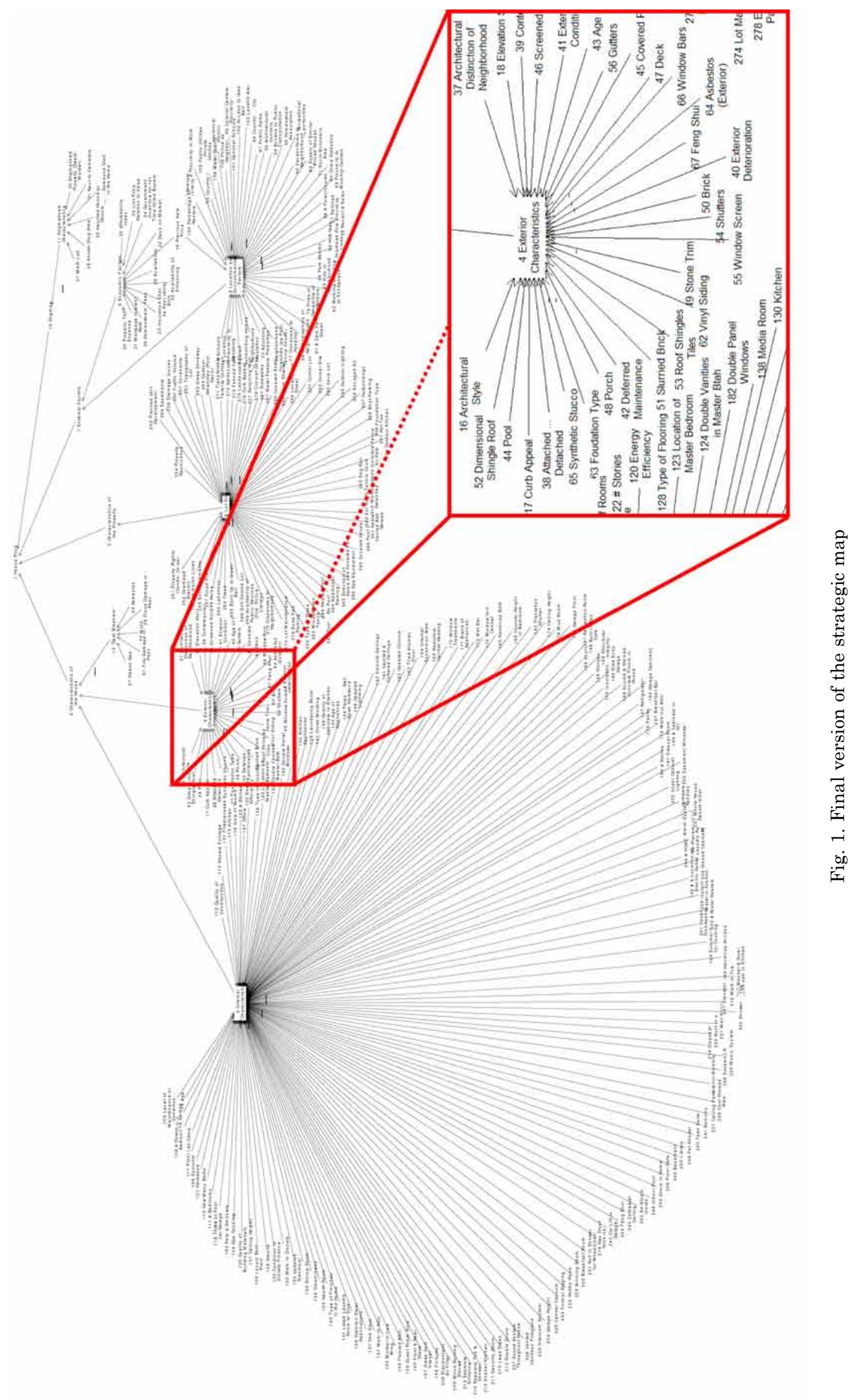


point of view) to estimate residential housing market values. This technical interactive step allowed a tree of criteria to be constructed, which was considered of extreme relevance to improve transparency and increase the understanding of the cause-and-effect relationships among identified FPVs. As a structuring procedure, the transition from the strategic map to the tree of criteria was subjective in nature and strongly dependent on the facilitators' skills. Again, while this may be seen as an important shortcoming, one should bear in mind that the MCDA approach indorses that all decision making is inherently subjective; and integrating subjectivity with objective data is one of the major contributions of this approach (cf. Santos et al. 2002).

With the support of the M-MACBETH software, the panel members were allowed to discuss the tree and encouraged to introduce changes in accordance to their own collective perceptions. Following Ferreira et al. (2011a), the properties of the tree were also tested. Representing the decision makers' interpretation of the problem, the final structure of the tree is illustrated in Figure 2, where the FPVs are marked in bold.

Following the decision makers' interpretation of the tree, $\mathrm{FPV}_{1}$ (Internal Characteristics) concerns internal physical characteristics of the house. Internal characteristics will be considered good or bad depending on variables such as: quality of construction, floor plan, interior amenities, size, kitchen and bath conditions; $\mathrm{FPV}_{2}$ (Exterior Characteristics) addresses issues in terms of exterior physical characteristics of the house. It seeks to introduce evaluation references into the decision process such as layout/architecture attractiveness, condition, exterior amenities (e.g. pool, deck, porch) and existence of drawbacks; $\mathrm{FPV}_{3}$ (Externalities or

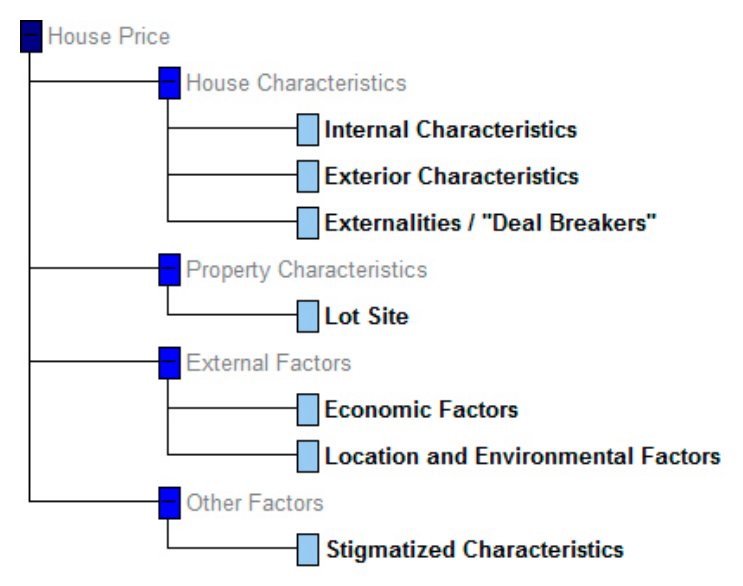

Fig. 2. Tree of points of view
"Deal Breakers") is defined in order to introduce concerns in terms of past damages and/or dangerous materials. For example, concerns regarding radon gas, mold, asbestos and flood or fire damages in the past are introduced in the appraisal system by this criterion; $\mathrm{FPV}_{4}$ (Lot Site) concerns evaluation references related to the property, such as: topography, street location, amenities, view and size; $\mathrm{FPV}_{5}$ (Economic Factors) highlights the importance of economic factors, such as: expenses (e.g. taxes, insurances), financing conditions and housing supply; $\mathrm{FPV}_{6}$ (Location and Environmental Factors) addresses issues related to location of the house and surrounding environment, namely: quality of schools, neighborhood safety and reputation, proximity to economic agents (e.g. hospitals, shopping) and accessibilities; and, finally, $\mathrm{FPV}_{7}$ (Stigmatized Characteristics) concerns issues related to social stigmas, such as: proximity to cemeteries, proximity to meth labs or known drug areas, haunting and ghosts and past deaths in the house. As argued by the members, some of the criteria included in our framework are rarely taken into account. However, the use of cognitive maps in this particular context allowed for their identification, and this was considered extremely positive by the participants involved.

With the tree of criteria validated, the participants were asked to construct a descriptor and respective impact levels for each FPV. This technical procedure allowed establishing a proper basis for value judgments projection. For example, FPV $_{6}$ (i.e. Location and Environmental Factors) becomes operational based on a descriptor of seven ordered reference levels $\left(L_{i}\right.$ with $\left.i=1,2, \ldots, 7\right)$, which assesses the physical location of a house, while it balances several aspects, namely: quality of schools, neighborhood reputation, proximity to economic agents and accessibilities (Table 1).

According to the decision makers' interpretation of the descriptor presented in Table 1, the greater the quality of schools and the neighborhood safety, balanced with the proximity to economic agents and accessibilities, the higher the house's partial score. It should also be noted that in addition to an upper and a lower impact levels, good and neutral levels were also considered to facilitate comparisons (for further details on the importance of reference points (or "anchors") to estimate appraised value, see Diaz, Hansz 2001). In practice, this procedure served a basis for sorting the impact levels and obtaining value functions in each FPV. Given a complete definition of impact levels in each FPV, the evaluation part was initiated. 
Table 1. Descriptor and impact levels for $\mathrm{FPV}_{6}$

\begin{tabular}{|c|c|c|}
\hline Impact levels & Reference levels & Description \\
\hline $\mathrm{L}_{1}$ & & $\begin{array}{l}\text { Great schools; Great neighborhood reputation; Gated community; Safe neighborhood; } \\
\text { Close to economic agents ("Best Option"). }\end{array}$ \\
\hline $\mathrm{L}_{2}$ & & $\begin{array}{l}\text { Good schools; Good-safe neighborhood; Close to economic agents (e.g. hospitals, shop- } \\
\text { ping); Good accessibilities. }\end{array}$ \\
\hline $\mathrm{L}_{3}$ & Good & $\begin{array}{l}\text { Good schools; Safe neighborhood; Close to economic agents (e.g. hospitals, shopping); } \\
\text { Good accessibilities. }\end{array}$ \\
\hline $\mathrm{L}_{4}$ & Neutral & Good schools, Safe neighborhood, Far from economic agents, Limited accessibilities. \\
\hline $\mathrm{L}_{5}$ & & Poor schools; Safe neighborhood; Close to economic agents; Good accessibilities. \\
\hline $\mathrm{L}_{6}$ & & Poor schools; Safe neighborhood; Far from economic agents; Limited accessibilities. \\
\hline $\mathrm{L}_{7}$ & & Poor schools; Unsafe neighborhood; Far from economic agents; Limited Accessibilities. \\
\hline
\end{tabular}

\subsection{The evaluation part}

The evaluation part was initiated with a third group work session. As described in the following subsections, this group workshop was important to calculate the trade-offs/compensations among impact levels and among FPVs. The MACBETH approach was applied during this phase.

\subsubsection{Value judgments and local preferences}

The definition of a local preference scale for each one of the descriptors created is easier if based on the construction of value matrices. In our study, the matrices were filled following the MACBETH approach, which is based on a set of predefined categories of semantic differences of attractiveness. Specifically: $\mathrm{C}_{0}-$ null; $\mathrm{C}_{1}$ - very weak; $\mathrm{C}_{2}-$ weak; $\mathrm{C}_{3}-$ moderate; $\mathrm{C}_{4}-$ strong; $\mathrm{C}_{5}-$ very strong; and $\mathrm{C}_{6}$ - extreme (cf. Bana e Costa et al. 1999, 2008).

During the third session, the panel members were asked to pairwise compare impact levels in terms of difference of attractiveness. As an example, for $\mathrm{FPV}_{6}$ (Location and Environmental Factors) (shown in Table 1), the panel needed to determine the difference of attractiveness between $\mathrm{L}_{1}$ and $\mathrm{L}_{2}$. Next, how did $\mathrm{L}_{1}$ compare to $\mathrm{L}_{3}$ ? In essence, we completed the grid shown in Figure 3.

Grounded on numerical representations of semi-orders for multiple thresholds (Doignon 1984), the MACBETH approach was developed by Carlos Bana e Costa and Jean-Claude Vansnick in the early 1990s (cf. Bana e Costa et al. 1994, 1999).

\begin{tabular}{|c|c|c|c|c|c|c|c|}
\hline 踾 & L1 & L2 & L3 & L4 & L5 & L6 & L7 \\
\hline L1 & no & wweak-weak & weak & moderate & strong & v. strong & extreme \\
\hline L2 & & no & very weak & weak & strong & v. strong & extreme \\
\hline L3 & & & no & weak & strong & v. strong & extreme \\
\hline L4 & & & & no & strong & v. strong & extreme \\
\hline L5 & & & & & no & weak-mod & strong \\
\hline L6 & & & & & & no & strong \\
\hline L7 & & & & & & & no \\
\hline
\end{tabular}

Fig. 3. Value judgments
As discussed by the authors, given a structure of binary relationships $\left[P^{(1)}, P^{(2)}, \ldots, P^{(k)}\right]$ (where the preference $P^{(k)}$ is stronger the greater the $k$ ), the numerical codification of semantic preferences becomes possible. More specifically, considering $X=$ $\{a, b, \ldots, n\}$ as a finite set of $n$ choice alternatives (or actions), the technical procedure consists in representing each choice alternative of $X$ by a certain value $x$, which results from a value function $v($.$) :$ $X \rightarrow R$, such that differences as $v(a)-v(b)$ (with $a$ $P b$ (i.e. $a$ strictly more attractive than $b$ )) are as compatible as possible with the decision makers' semantic preferences (see also Jacquet-Lagrèze, Siskos 2001). Moreover, for all pairs of choice alternatives $(a, b)$ associated to the same category $C$, the differences $v(a)-v(b)$ will be allocated to the same interval, without any overlap. Technically, if $a$ is considered more attractive than $b$ and the difference between both choice alternatives is moderate, then $(a, b) \in C_{3}$. According to Bana e Costa et al. (2008), whereas two contiguous ranges correspond to two consecutive categories, the procedure consists in the association of asymmetric partitions of the ray of positive real numbers to partition classes of ordered pairs $(a, b)$ (with $a P b$ ) (see also Bana e Costa et al. 2012). In this sense, intervals between consecutive categories of differences of attractiveness are naturally introduced based on a value function $v$ and function thresholds $s_{k}$ as defined in formulation (1):

$$
a P^{(k)} b: \quad s_{k}<v(a)-v(b)<s_{k+1} \text {. }
$$

From the practical point of view, because the thresholds $s_{k}$ are positive real constants, the definition of intervals between categories becomes easier (Bana e Costa et al. 2005). As such, grounded on the decision makers' value preferences, the procedure consists in allocating the difference of attractiveness between each pair of choice alternatives $(a, b) \in X$ to one of the semantic categories mentioned herein. In doing so, formulations (2) 
and (3) presented below should be considered for consistency purposes (Junior 2008):

$$
\begin{gathered}
\forall a, b \in X: v(a)>v(b) \Leftrightarrow a P b, \\
\forall k, k^{*} \in\{1,2,3,4,5,6\}, \forall a, b, c, d \in X \text { with }(a, b) \in C_{k} \\
\text { and }(c, d) \in C_{k^{*}}: k \geq k^{*}+1 \Rightarrow v(a)-v(b) \geq v(c)-v(d) .
\end{gathered}
$$

According to formulation (2), if alternative $a$ is strictly more attractive than alternative $b$ (i.e. $a$ $P b$ ), then the value of $a$ should be greater than the value of $b$ (i.e. $v(a)>v(b)$ ). Logically, $v(a)=$ $v(b)$ means that no difference between choice alternatives is felt. In this case, alternative $a$ is as attractive as alternative $b$ (i.e. $a I b$ ) and, consequently, the pair $(a, b) \in C_{0}$. Grounded on the semantic categories $C_{k}$ presented at the beginning of this subsection, and following Bana e Costa et al. (2008: 28), formulation (3) assumes "that all of the differences allocated to one semantic preference difference category are strictly larger than those allocated to a lower category".

Once the consistency of the value judgments has been analyzed, linear programming is applied according to formulation (4) (Junior 2008; Ferreira et al. 2012). This allows an initial scale to be generated, which should serve as a negotiation tool among the decision makers:

$\operatorname{Minv}(n)$

$$
\begin{aligned}
& \text { S.T. }: \forall a, b \in X: a P b \Rightarrow v(a) \geq v(b)+1 \\
& \forall a, b \in X: a I b \Rightarrow v(a)=v(b) \\
& \forall(a, b),(c, d) \in X, \text { if the difference of } \\
& \text { attractiveness between } \\
& \quad a \text { and } b \text { is bigger than between } \\
& \quad c \text { and } d \text {,then: } \\
& \quad v(a)-v(b) \geq v(c)-v(d)+1+\delta(a, b, c, d)
\end{aligned}
$$

$v\left(a^{-}\right)=0$

where:

$n$ is an element of $X$ so that $\forall a, b, c, \ldots$

$\in X: n(P \cup I) a, b, c, \ldots$

$a^{-}$is an element of $X$ so that $\forall a, b, c, \ldots$

$\in X: a, b, c, \ldots(P \cup I) a^{-}$

$\delta(a, b, c, d)$ is the minimal number of categories

of difference of attractiveness

between the difference of attractiveness

between $a$ and $b$ and the difference

of attractiveness between $c$ and $d$.

Following formulation (4), it is worth noting that $n$ is the most attractive alternative of $X$ (or at least as attractive as the others; i.e. $n(P \cup I) a$,
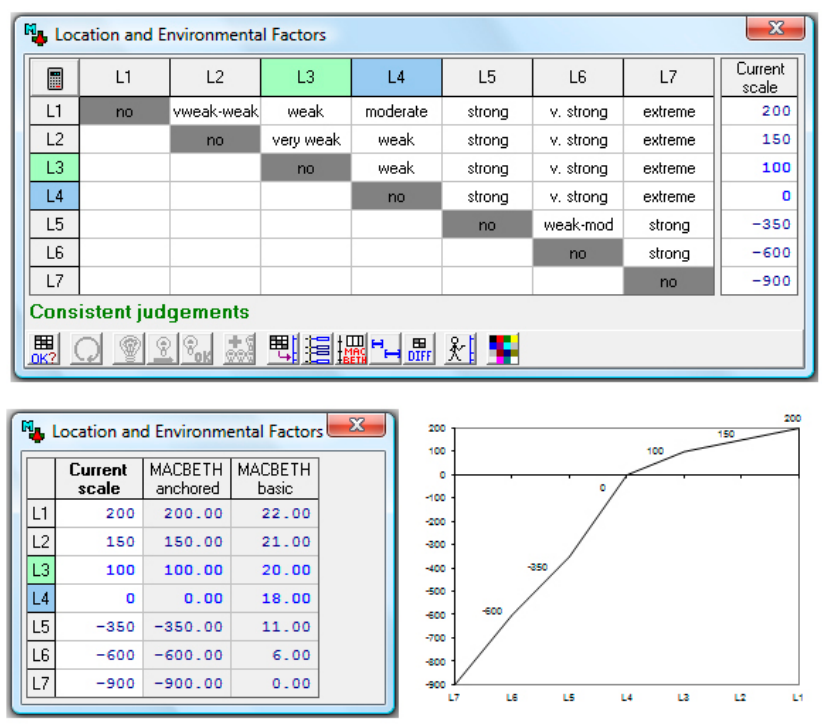

Fig. 4. Value judgments, proposed value scale and function of the $\mathrm{FPV}_{6}$

$b, c, \ldots)$, and its value minimization is required to safeguard the minimal length of the initial scale. Contrarily, $a^{-}$is the least attractive choice alternative of $X$ (or at least as attractive as the others; i.e. $\left.a, b, c, \ldots(P \cup I) a^{-}\right)$, and its value represents the "zero" of the scale (for a deeper technical discussion, see Bana e Costa et al. 2008). According to formulation (4), Figure 4 illustrates the procedure used to achieve the $\mathrm{FPV}_{6}$ value function. It is worth highlighting, however, that this procedure was repeatedly executed until a local preference scale for each descriptor was obtained.

Following Figure 4, it is worth noting the usefulness of the M-MACBETH software in providing decision makers with the opportunity to express their values using semantic judgments, which are considered a more natural form of value projection (cf. Bana e Costa, Chagas 2004). Additionally, the software used was very valuable in offering opportunities to overcome technical inconsistencies. At this stage, and with the aim of guaranteeing preferential independence among preferences, mutual preferential independence tests were also conducted (for technical details, see Bana e Costa, Chagas 2004; Bana e Costa et al. 2005). Once cardinal value scales (i.e. local scales) were obtained, the next procedural step consisted of calculating weights (i.e. trade-offs) for the FPVs.

\subsubsection{The trade-off procedures}

Also in the third session, the panel members were next asked to rank the FPVs considered in the model in terms of overall attractiveness to obtain trade-offs among FPVs. This stage in the process was very similar to the previous step, but rather 
than comparing impact levels within each FPV, the participants were asked to make comparisons among the different FPVs. This step was supported on a matrix of cognitive comparisons, which allowed the experts to compare an alternative $a_{n}$ (composed of the best impact levels) to an alternative $a_{0}$ (composed of the worst impact levels) (for technical aspects, see Bana e Costa, Chagas 2004). Following the same technical procedure used for the local scales calculi (cf. Figs 3 and 4), the experts were then asked to express semantic judgments regarding the difference of attractiveness among the previously ordered FPVs. An initial MACBETH scale and correspondent compensation rates were then presented for analysis and discussion, as illustrated in Figure 5.

After discussion, the substitution rates presented in Figure 5 were consensually approved by the decision makers, and this approval allowed for the application of a simple additive value model as
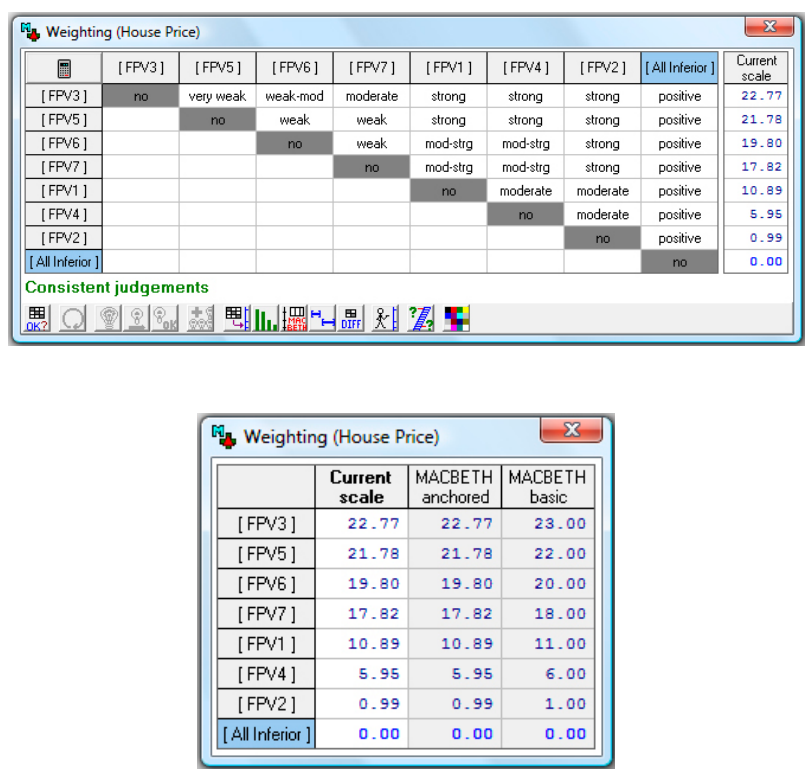

Fig. 5. Criteria weights presented in formulation (5) (Bana e Costa et al. 2008):

$$
\begin{gathered}
V(a)=\sum_{i=1}^{n} x_{i} v_{i}(a) \text { with } \sum_{i=1}^{n} x_{i}=1 \\
\text { and } x_{i}>0 \text { and }\left\{\begin{array}{l}
v_{i}\left(\text { good }_{i}\right)=100 \\
v_{i}\left(\text { neutral }_{i}\right)=0
\end{array}\right.
\end{gathered}
$$

Technically, the additive model presented in formulation (5) allows for the calculation of the overall score $V(a)$ through the aggregation of the partial scores $v_{i}(a)$, where $w_{i}$ is the weight of criterion $i$. This overall score is a holistic measure of performance and is important to assist in estimating the offer price of a residence. To facilitate cognitive comparisons among choice alternatives (i.e. houses in this case), two specific performance levels - good and neutral - were defined for each descriptor. The respective partial scores of these two reference levels are presented in formulation (5) as $v_{i}\left(\right.$ good $\left._{i}\right)$ and $v_{i}\left(\right.$ neutral $\left._{i}\right)$.

\subsubsection{Estimating residential housing sale}

The process of estimating residential housing offer prices was initiated in a fourth and last group session. Four fictitious houses (called Alphas) were introduced in the model to promote cognitive comparisons and provide decision makers with a starting point for price estimation based on the respective overall performance scores. This procedure was accomplished based on the cardinal value functions previously defined. This step in the process was very valuable both to test our appraisal system in functional terms and increase the interest of the participants. At this stage, it should be explained that Alpha 1 stands for a house that performs at the best level for all FPVs; Alpha 2 stands for a house that performs at all good levels; Alpha 3 represents a house that is not considered attractive or unattractive and, as such, performs at a neutral

Table 2. Impact levels and performance values revealed by the Alphas

\begin{tabular}{lllllllll}
\hline & Overall & $\mathrm{FPV}_{1}$ & $\mathrm{FPV}_{2}$ & $\mathrm{FPV}_{3}$ & $\mathrm{FPV}_{4}$ & $\mathrm{FPV}_{5}$ & $\mathrm{FPV}_{6}$ & $\mathrm{FPV}_{7}$ \\
\hline Alpha 1 & 207.93 & $\mathrm{~L}_{1}$ & $\mathrm{~L}_{1}$ & $\mathrm{~L}_{1}$ & $\mathrm{~L}_{1}$ & $\mathrm{~L}_{1}$ & $\mathrm{~L}_{1}$ & $\mathrm{~L}_{1}$ \\
& & 200 & 200 & 200 & 266.67 & 300 & 200 & 100 \\
Alpha 2 & \multirow{2}{*}{100} & $\mathrm{~L}_{5}$ & $\mathrm{~L}_{3}$ & $\mathrm{~L}_{2}$ & $\mathrm{~L}_{4}$ & $\mathrm{~L}_{3}$ & $\mathrm{~L}_{3}$ & $\mathrm{~L}_{1}$ \\
& & 100 & 100 & 100 & 100 & 100 & 100 & 100 \\
Alpha 3 & 0 & $\mathrm{~L}_{7}$ & $\mathrm{~L}_{4}$ & $\mathrm{~L}_{3}$ & $\mathrm{~L}_{6}$ & $\mathrm{~L}_{4}$ & $\mathrm{~L}_{4}$ & $\mathrm{~L}_{2}$ \\
& & 0 & 0 & 0 & 0 & 0 & 0 & 0 \\
Alpha 4 & -1063.88 & $\mathrm{~L}_{12}$ & $\mathrm{~L}_{9}$ & $\mathrm{~L}_{7}$ & $\mathrm{~L}_{9}$ & $\mathrm{~L}_{8}$ & $\mathrm{~L}_{7}$ & $\mathrm{~L}_{5}$ \\
& & -900 & -1700 & -950 & -1233.33 & -1800 & -900 & -500 \\
\hline Weights & & 0.1089 & 0.0099 & 0.2277 & 0.0595 & 0.2178 & 0.1980 & 0.1782 \\
\hline
\end{tabular}


level for all FPVs; and, finally, Alpha 4 stands for a house that performs at the worst level for all FPVs. Table 2 shows the performance values of the four Alphas, which served as anchored references for price estimation.

As mentioned before, each Alpha's overall score resulted from the aggregation of the local ratings according to the additive model presented in formulation (5). Based on the overall scores calculated, and considering the Alphas' partial performance in terms of FPVs, the panel members were asked to associate a price to each one of the four Alphas. This procedural step provided the basis for more discussion and supported cognitive comparisons allowing the decision makers to estimate a price for each Alpha. Table 3 presents the prices proposed by the group.

Table 3. Estimated price for the Alphas

\begin{tabular}{lll}
\hline & Overall score & Estimated price \\
\hline Alpha 1 & 207.93 & $\$ 3,500,000.00$ \\
Alpha 2 & 100 & $\$ 220,000.00$ \\
Alpha 3 & 0 & $\$ 132,150.00$ \\
Alpha 4 & -1063.88 & $\$ 1,200.00$ \\
\hline
\end{tabular}

At this stage of the process, residential real estate price estimation became possible thought the application of linear interpolation. As an illustrative example, Alpha 5 represents a house with the profile presented in Table 4 and Figure 6. Note that $\mathrm{L}_{\mathrm{i}}$ is the performance level determined by the decision makers for each Alpha in each of the FPVs. The scores and the weights were determined using the MACBETH approach.

Based on the estimated prices presented in Table 3, and considering the overall score of Alpha 5 , the correspondent price would be approximately $\$ 129,950.00$ (i.e. after applying linear interpolation). Our evaluation system will increase in accuracy and precision with the introduction of additional actual sales data. More specifically, with linear interpolation, the intervals between scores and prices decrease with an increasing number of actual sales introduced into the model. Consequently, the predictive error will tend to decrease accordingly. Thus, one of the major contributions of the MCDA framework is to integrate subjectivi-

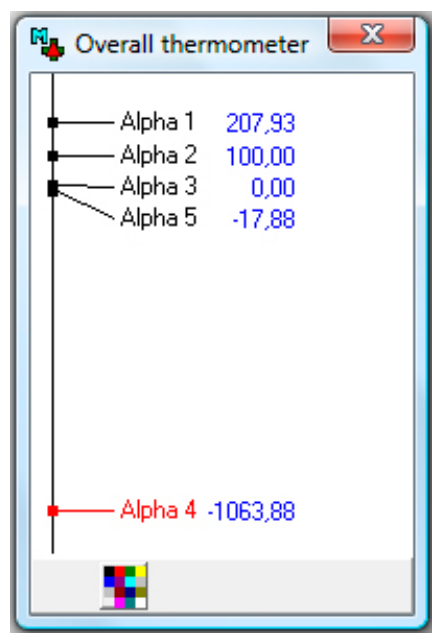

Fig. 6. Overall position of Alpha 5

ty and transparency with objective data. Moreover, although rakings were not the major objective of our evaluation system, the ordering of the Alphas revealed to be very valuable to support accurate price estimation.

Due to the degree of subjectivity associated to the process, decision makers were invited, at the end of the fourth session, to discuss the results and present advantages and disadvantage of the proposed framework. The decision makers were overall very excited and supportive of this valuation process.

\subsubsection{Testing the process and the new system with actual sales data}

After discussing and validating the results achieved during the previous four group meetings, we conducted a last session (i.e. the fifth) in order to: (1) test our MCDA-based framework with actual sales data; and (2) get feedback on the results obtained. The attainment of these two objectives would provide important information to assess/strengthen the practical relevance of the process we have followed to design the appraisal system and of the framework in itself. In this sense, we began the session by asking one of the decision makers (i.e. the realtor who provided us with actual sales data) to complete a matrix of partial evaluations. Recalling that one of features of the MCDA approach is reduced need of data (cf. Belton, Stewart 2002; Ferreira et al. 2011b), we used initial information

Table 4. Alpha 5 partial performance and respective overall score

\begin{tabular}{lllllllll}
\hline & Overall & $\mathrm{FPV}_{1}$ & $\mathrm{FPV}_{2}$ & $\mathrm{FPV}_{3}$ & $\mathrm{FPV}_{4}$ & $\mathrm{FPV}_{5}$ & $\mathrm{FPV}_{6}$ & $\mathrm{FPV}_{7}$ \\
\hline Alpha 5 & -17.88 & $\mathrm{~L}_{5}$ & $\mathrm{~L}_{3}$ & $\mathrm{~L}_{3}$ & $\mathrm{~L}_{7}$ & $\mathrm{~L}_{5}$ & $\mathrm{~L}_{2}$ & $\mathrm{~L}_{2}$ \\
& & 100 & 100 & 0 & -633.33 & -100 & 150 & 0 \\
\hline Weights & & 0.1089 & 0.0099 & 0.2277 & 0.0595 & 0.2178 & 0.1980 & 0.1782 \\
\hline
\end{tabular}


regarding 16 houses (i.e. eleven called Deltas from now on, plus the four Alphas defined by the group in the fourth group session (i.e. Best, Good, Neutral and Worst) and Alpha 5 that was created for exemplificative purposes). Following previous MCDA frameworks (e.g. Ferreira et al. 2012, 2014a), this was considered enough to start testing the process and the framework developed.

This phase of the session was fruitful in terms of results consolidation, namely because the decision maker expressed some difficulty with the results obtained for some of the Deltas. This justified the need for careful comparison of the impact profiles of the eleven Deltas, including an analysis of their distance against the five Alphas, which allowed for a deeper understanding of the results obtained and the introduction of (small) adjustments in the framework. Still, the evaluation system was considered flexible enough to be adopted. Table 5 shows the evaluation exercise of the realtor.

The information provided in Table 5 allowed us to increase the number of anchored references, which, recalling the discussion about linear interpolation (cf. subsection 3.2.3), allows for price estimations and, furthermore, decreases in the predictive error (Table 6).

Finally, the next procedural step consisted in using the anchored references presented in Table 6 (i.e. the Alphas and Deltas) to estimate the price of a set of houses (called Betas from now on). Table 7 presents the evaluation exercise of the realtor regarding five randomly chosen Betas. As can be seen, the application of linear interpolation after calculation of the Betas' overall scores allowed us to estimate a price for each Beta. Furthermore, we calculate an estimation error for each housing sale
Table 6. Overall scores and sale prices of the Deltas (and Alphas) evaluated

\begin{tabular}{lll}
\hline House & Overall score & Sale price $^{3}$ \\
\hline Alpha 1 ('Best') & 207.93 & $\$ 3,500,000$ \\
Delta 11 & 164.37 & $\$ 1,300,000$ \\
Delta 01 & 152.98 & $\$ 650,000$ \\
Delta 07 & 147.03 & $\$ 620,000$ \\
Delta 03 & 130.45 & $\$ 398,000$ \\
Delta 05 & 129.42 & $\$ 341,000$ \\
Delta 10 & 128.97 & $\$ 245,000$ \\
Alpha 2 ('Good') & 100.00 & $\$ 220,000$ \\
Delta 04 & 49.01 & $\$ 157,000$ \\
Delta 06 & 42.82 & $\$ 135,900$ \\
Delta 09 & 39.60 & $\$ 134,900$ \\
Alpha 3 ('Neutral') & 0.00 & $\$ 132,150$ \\
Alpha 5 ('Example') & -17.88 & $\$ 129.950$ \\
Delta 02 & -29.70 & $\$ 74,500$ \\
Delta 08 & -506.88 & $\$ 29,000$ \\
Alpha 4 ('Worst') & -1063.88 & $\$ 1,200$ \\
\hline 1 Reference values obtained during the 4th Group session. \\
2 Illustrative example from subsection 3.2 .3$. \\
3 Data from Crye-Leike Realtors (excluding the Alphas).
\end{tabular}

by comparing estimated prices with actual sale prices. An estimation error of approximately $14 \%$ for Beta 5 is explainable because Beta 5 is a mansion and significantlyoutside of the price range of the other properties; however, the results are encouraging because all the other estimation errors are below 5\%. Estimation errors tend to decrease with the introduction of additional Alphas, Deltas or Betas as discussed in subsection 3.2.3. Figure 7 presents the value function obtained.

In line with the results achieved during the last group meeting, the decision maker recognized the

Table 5. Partial performance of the 11 Deltas evaluated

\begin{tabular}{|c|c|c|c|c|c|c|c|c|c|c|c|c|c|c|c|}
\hline House & $\mathrm{FPV}_{1}$ & $\mathrm{FPV}_{2}$ & $\mathrm{FPV}_{3}$ & $\mathrm{FPV}_{4}$ & $\mathrm{FPV}_{5}$ & $\mathrm{FPV}_{6}$ & $\mathrm{FPV}_{7}$ & $\begin{array}{l}\text { Partial } \\
\text { value } \\
\mathrm{FPV}_{1}\end{array}$ & $\begin{array}{l}\text { Partial } \\
\text { value } \\
\mathrm{FPV}_{2}\end{array}$ & $\begin{array}{l}\text { Partial } \\
\text { value } \\
\mathrm{FPV}_{3} \\
\end{array}$ & $\begin{array}{l}\text { Partial } \\
\text { value } \\
\text { FPV }_{4} \\
\end{array}$ & $\begin{array}{l}\text { Partial } \\
\text { value } \\
\mathrm{FPV}_{5} \\
\end{array}$ & $\begin{array}{l}\text { Partial } \\
\text { value } \\
\text { FPV }_{6} \\
\end{array}$ & $\begin{array}{l}\text { Partial } \\
\text { value } \\
\mathrm{FPV}_{7} \\
\end{array}$ & $\begin{array}{l}\text { Sale } \\
\text { price }^{1}\end{array}$ \\
\hline Delta 01 & $\mathrm{~L}_{1}$ & $\mathrm{~L}_{1}$ & $\mathrm{~L}_{2}$ & $\mathrm{~L}_{1}$ & $\mathrm{~L}_{3}$ & $\mathrm{~L}_{1}$ & $\mathrm{~L}_{1}$ & 200.00 & 200.00 & 150.00 & 266.67 & 100.00 & 200.00 & 100.00 & $\$ 650,000$ \\
\hline Delta 02 & $\mathrm{~L}_{7}$ & $\mathrm{~L}_{6}$ & $\mathrm{~L}_{3}$ & $\mathrm{~L}_{6}$ & $\mathrm{~L}_{2}$ & $\mathrm{~L}_{5}$ & $\mathrm{~L}_{2}$ & 0.00 & -400.00 & 0.00 & 0.00 & 200.00 & -350.00 & 0.00 & $\$ 74,500$ \\
\hline Delta 03 & $\mathrm{~L}_{5}$ & $\mathrm{~L}_{2}$ & $\mathrm{~L}_{2}$ & $\mathrm{~L}_{3}$ & $\mathrm{~L}_{3}$ & $\mathrm{~L}_{2}$ & $\mathrm{~L}_{1}$ & 100.00 & 150.00 & 175.00 & 150.00 & 100.00 & 150.00 & 100.00 & $\$ 398,000$ \\
\hline Delta 04 & $\mathrm{~L}_{8}$ & $\mathrm{~L}_{6}$ & $\mathrm{~L}_{3}$ & $\mathrm{~L}_{6}$ & $\mathrm{~L}_{3}$ & $\mathrm{~L}_{2}$ & $\mathrm{~L}_{1}$ & -150.00 & -400.00 & 0.00 & 0.00 & 100.00 & 150.00 & 100.00 & $\$ 157,000$ \\
\hline Delta 05 & $\mathrm{~L}_{3}$ & $\mathrm{~L}_{1}$ & $\mathrm{~L}_{2}$ & $\mathrm{~L}_{1}$ & $\mathrm{~L}_{2}$ & $\mathrm{~L}_{4}$ & $\mathrm{~L}_{1}$ & 175.00 & 200.00 & 115.00 & 266,67 & 200.00 & 25.00 & 100.00 & $\$ 341,000$ \\
\hline Delta 06 & $\mathrm{~L}_{7}$ & $\mathrm{~L}_{6}$ & $\mathrm{~L}_{3}$ & $\mathrm{~L}_{6}$ & $\mathrm{~L}_{3}$ & $\mathrm{~L}_{5}$ & $\mathrm{~L}_{1}$ & 0.00 & -400.00 & 75.00 & 0.00 & 100.00 & -50.00 & 100.00 & $\$ 135,900$ \\
\hline Delta 07 & $\mathrm{~L}_{2}$ & $\mathrm{~L}_{2}$ & $\mathrm{~L}_{1}$ & $\mathrm{~L}_{3}$ & $\mathrm{~L}_{3}$ & $\mathrm{~L}_{2}$ & $\mathrm{~L}_{1}$ & 200.00 & 150.00 & 200.00 & 150.00 & 100.00 & 150.00 & 100.00 & $\$ 620,000$ \\
\hline Delta 08 & $\mathrm{~L}_{9}$ & $\mathrm{~L}_{7}$ & $\mathrm{~L}_{3}$ & $\mathrm{~L}_{6}$ & $\mathrm{~L}_{7}$ & $\mathrm{~L}_{6}$ & $\mathrm{~L}_{4}$ & -325.00 & -725.00 & 0.00 & 0.00 & -1300.00 & -600.00 & -350.00 & $\$ 29,000$ \\
\hline Delta 09 & $\mathrm{~L}_{6}$ & $\mathrm{~L}_{2}$ & $\mathrm{~L}_{3}$ & $\mathrm{~L}_{6}$ & $\mathrm{~L}_{4}$ & $\mathrm{~L}_{4}$ & $\mathrm{~L}_{1}$ & 25.00 & 150.00 & 25.00 & 25.00 & 25.00 & 25.00 & 100.00 & $\$ 134,900$ \\
\hline Delta 10 & $\mathrm{~L}_{3}$ & $\mathrm{~L}_{1}$ & $\mathrm{~L}_{2}$ & $\mathrm{~L}_{1}$ & $\mathrm{~L}_{3}$ & $\mathrm{~L}_{2}$ & $\mathrm{~L}_{1}$ & 175.00 & 200.00 & 100.00 & 266.67 & 100.00 & 150.00 & 100.00 & $\$ 245,000$ \\
\hline Delta 11 & $\mathrm{~L}_{1}$ & $\mathrm{~L}_{1}$ & $\mathrm{~L}_{1}$ & $\mathrm{~L}_{1}$ & $\mathrm{~L}_{3}$ & $\mathrm{~L}_{1}$ & $\mathrm{~L}_{1}$ & 200.00 & 200.00 & 200.00 & 266.67 & 100.00 & 200.00 & 100.00 & $\$ 1,300,000$ \\
\hline
\end{tabular}

${ }^{1}$ Data from Crye-Leike Realtors. 


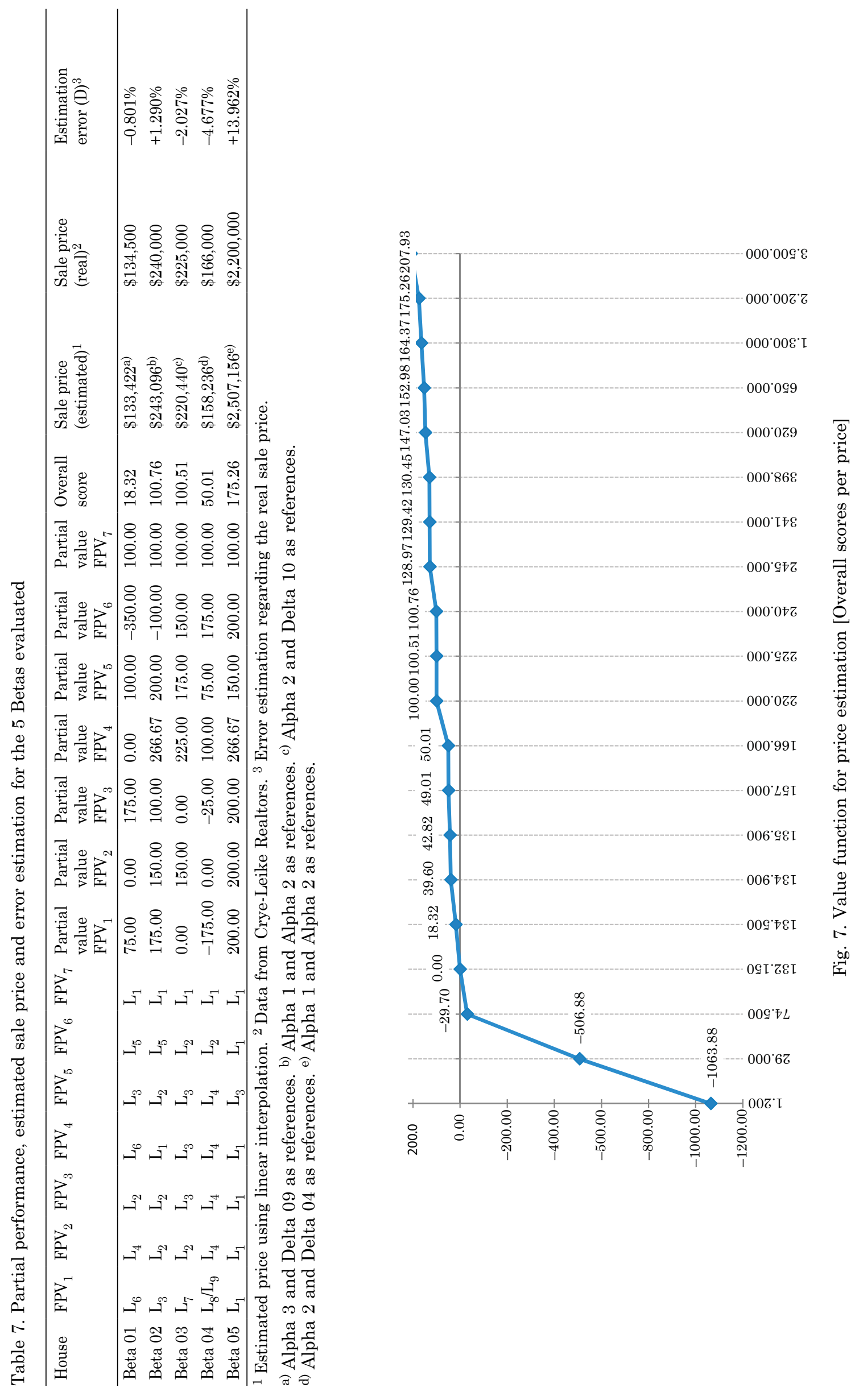




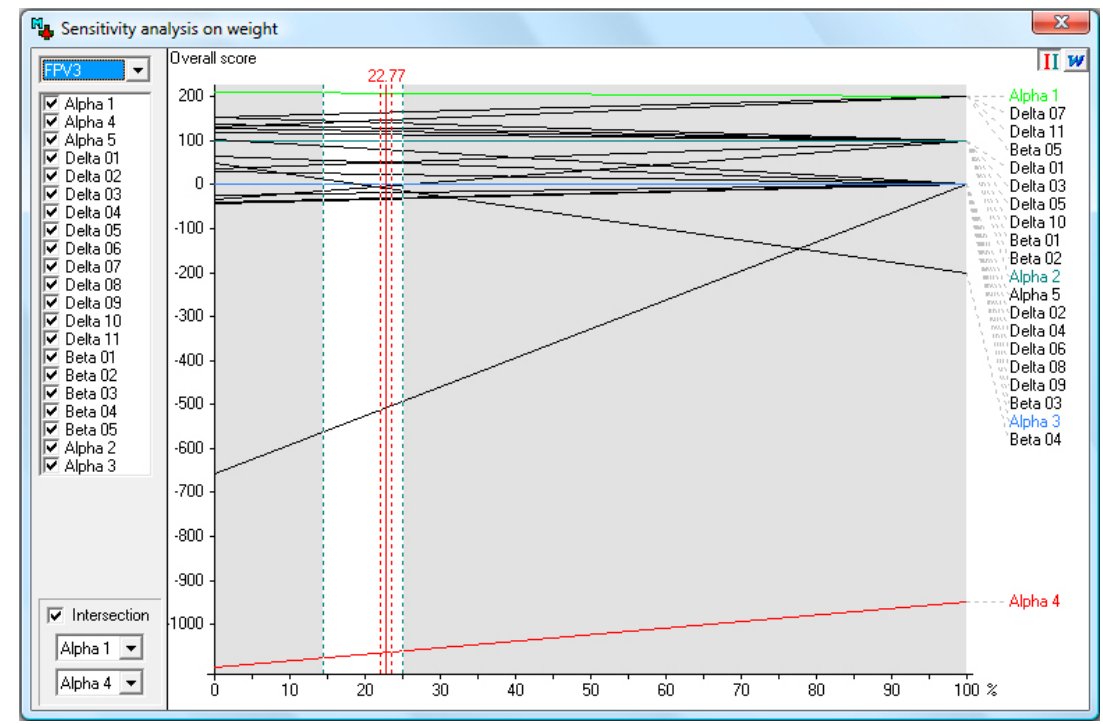

Fig. 8. Sensitivity analysis $\left[\mathrm{FPV}_{3}\right]$

potential of the methodologies used and of the assessment system derived to bring valuable insights to the process of establishing residential housing prices. However, because in some circumstances it may be difficult to rank the overall performance of some houses, and because the implementation of the framework would require the intervention of a facilitator (i.e. the facilitator's expertise is fundamental in dealing with techniques that are not known among realtors), we decided to strengthen our study by performing sensitivity analyses for all FPVs. These analyses were carried out using the M-MACBETH software. Figure 8 illustrates the sensitivity analysis performed for $\mathrm{FPV}_{3}$ (considered as the most important one).

As illustrated in Figure 8, the weight of $\mathrm{FPV}_{3}$ is 22.77 and the sensitivity analysis developed allows us to conclude that our appraisal system is strong because the $\mathrm{FPV}_{3}$ 's weight can vary considerably without compromising the Deltas' position and, implicitly, the value judgments of the group. Again, sensitivity analyses were carried out for all FPVs. It seems important to underline, however, that these analyses were carried out both to determine the stability of the proposed evaluation system and to serve as basis for recommendations.

\subsection{The recommendations part}

The MCDA-based framework developed in this study allows real estate professionals to: (1) discriminate homes according to a system that was developed based on their own experiences, perceptions and value judgments; (2) compare performances against cognitive references (i.e. Alphas);
(3) promote discussions throughout the process, which allowed for an increase in transparency in residential real estate price estimation; and (4) show the practicality of cognitive mapping and MACBETH in the particular context of estimating real estate values.

Although the system developed in this study achieved encouraging results in terms of residential real estate valuation and price estimation, namely as a result of the generalized receptiveness revealed by the panel members, one should bear in mind that the major reason for satisfaction is the process itself. As previously discussed, MCDA is not outcome- but process-oriented, where a non-prescriptive position is assumed. In fact, following Wolverton and Gallimore (1999), the appraisal framework was colored by negotiation and an experience-based learning orientation. As such, considering the versatility of the adopted technical procedures, our evaluation system may be used as a negotiation tool, which does not prescribe optimal solutions, but encourages discussion and promotes a better understanding of the evaluation factors associated with residential real estate price estimation. Furthermore, considering that results are strongly dependent on the circumstances and/ or participants involved, any generalization should be properly considered. Obviously, this can always be pointed out as one of the system's weaknesses. However, the combined use of cognitive mapping and MACBETH also offers improvement possibilities. Thus, we also recommend performing sensitivity and robustness analyses after any change in the framework. 


\section{DISCUSSION AND CONCLUSION}

Accurate estimates of real estate intrinsic values are a first step preceding sale price negotiations, and are of significant interest for sellers, buyers/ investors and lending institutions. However, as discussed above, residential real estate market value estimation is complex, and a number of approaches are currently used, including use of comparables and hedonic pricing models. Residential real estate prices, because of multiple and conflicting stakeholder interests, can deviate from fundamental intrinsic values due to a variety of factors considered in a house evaluation process. This deviation is particularly evident in scenarios of economic adversity, where it is imperative to understand the mechanisms of "internal operational performance [price estimation mechanisms]" (Wu 2012: 303).

The property valuation field has made remarkable progress where a number of flexible functional forms have been developed, including: nonparametric or semi-parametric regressions and spatial models that capture correlations within submarkets allowing for temporal asymmetry (e.g. Bourassa et al. 2010; Osland 2010). However, issues still remain in terms of the process through which valuation criteria are defined and the way that compensation rates among criteria/attributes are calculated. We use cognitive mapping to support criteria selection, and apply MACBETH to calculate the trade-offs. We believe that this is the first work that demonstrates how to integrate cognitive mapping and MACBETH in the real estate price estimation literature; and different decision makers can significantly benefit from the application of these two methodologies.

An appraisal system is developed to assist real estate professionals in estimating fair residential real estate initial offer prices. An important feature of our approach is that decisions leading to asking price estimation consider the perceptions of a group of different stakeholders (e.g. realtors, sellers, households). This approach, in terms of estimating initial asking prices, may be considered an alternative to and may consider factors not usually found in hedonic applications. Another important aspect of MCDA is that value estimation responds to housing market characteristics; i.e. the way trade-offs among criteria are calculated allows for dynamism and spatial and temporal versatility. Special emphasis may also be given to the fact that our valuation system represents a process-oriented application, considering that decisions in this particular context are not easily taken and greatly depend on several individuals with different and often conflicting standpoints. From this premise, searching for optimal solutions in this particular domain seems to be unrealistic.

We provide evidence that the integration of cognitive maps and MACBETH holds significant potential for strategic planning by assisting real estate professionals in obtaining consolidated information to: (1) discriminate homes according to a system that was developed based on their own experiences, perceptions and value judgments; (2) compare the relative positions of the evaluated houses against cognitive references (i.e. Alphas); and (3) promote discussions throughout the process, which allows for an increase in transparency in residential real estate price estimation.

The results of our application of cognitive mapping and MCDA to real estate valuation are appealing. As stated above, we advise caution when relying on the outputs due to the dependence on circumstances and locations, and the selection of professionals involved in the study. The process is inherently subjective in measurement choices and respective weighting; however, while this can be suggested as a possible shortcoming, it should also be highlighted that valuation is subjective in nature and one of the approach's greatest contributions is to make such subjectivity explicit and integrated with objective data (cf. Ackermann, Eden 2001; Belton, Stewart 2002; Nowak 2011; Filipe et al. 2015).

Future research may consider: (1) increasing the number of actual sales (i.e. the system's effectiveness is yet to be confirmed by practical application on a large scale); (2) organizing a panel study with another set of decision makers in the same region to determine the robustness of the results achieved; (3) organizing a panel study within another region to increase generalizability; (4) conducting a survey to receive feedback from more decision makers and, thus, increase the reliability of the results; and (5) developing a comparative essay and analyzing the results obtained from the application of other techniques in the context of this study. Furthermore, we recommend assessing the impact of the 2008-2010 financial crisis on the process of valuation of residential real estate.

\section{ACKNOWLEDGMENTS}

Previous and non-copyrighted versions of this paper were presented at the 28th and 29th Annual American Real Estate Society Meetings (St. Petersburg Beach, Florida, April 2012; and Kohala 
Coast, Big Island of Hawaii, April 2013), and at the 2015 BAI International Conference, held in Macau, China, July 2015. The authors gratefully acknowledge the institutional support of the Memphis Area Association of Realtors, Crye-Leike Realtors, Integra Realty Resources, and the superb contribution and infinite willingness of the panel members: Carol Ann Burns, Cheryl Lamghari, David Ralph, Jamison Walter Allen, Mark Sunderman, Ralph Allen McCool and Tommie CriswellJones. The authors also acknowledge David H. Downs (our discussant), Virginia Commonwealth University, for his helpful comments and suggestions. Financial support for this research has been provided by the Morris Fogelman Real Estate Chair Excellence, University of Memphis.

\section{REFERENCES}

Ackermann, F.; Eden, C. 2001. SODA - journey making and mapping in practice, in J. Rosenhead, J. Mingers (Eds.). Rational analysis for a problematic world revisited: Problem structuring methods for complexity, uncertainty and conflict. $2^{\text {nd }}$ ed. Chichester: John Wiley \& Sons, 43-60.

Balarine, O. 2004. The use of appraisal techniques in property development, Revista Produção 14(2): 47-57.

Bana e Costa, C.; Chagas, M. 2004. A career choice problem: an example of how to use MACBETH to build a quantitative value model based on qualitative value judgements, European Journal of Operational Research 153(2): 323-331. http://dx.doi.org/10.1016/ S0377-2217(03)00155-3

Bana e Costa, C.; Vansnick, J. 1994. MACBETH: an interactive path towards the construction of cardinal value functions, International Transactions in Operational Research 1(4): 489-500. http://dx.doi. org/10.1016/0969-6016(94)90010-8

Bana e Costa, C.; De Corte, J.; Vansnick, J. 2005. On the mathematical foundations of MACBETH, in J. Figueira, S. Greco, M. Ehrgott (Eds.). Multiple criteria decision analysis: the state of the art surveys. New York: Springer, 409-442.

Bana e Costa, C.; De Corte, J.; Vansnick, J. 2012. MACBETH, International Journal of Information Technology and Decision Making 11(2): 359-387. http:// dx.doi.org/10.1142/S0219622012400068

Bana e Costa, C.; Ensslin, L.; Corrêa, E.; Vansnick, J. 1999. Decision support systems in action: Integrated application in a multicriteria decision aid process, European Journal of Operational Research 113(2): 315-335. http://dx.doi.org/10.1016/S03772217(98)00219-7

Bana e Costa, C.; Lourenço, J.; Chagas, M.; Bana e Costa, J. 2008. Development of reusable bid evaluation models for the Portuguese electric transmission company, Decision Analysis 5(1): 22-42. http://dx.doi. org/10.1287/deca.1080.0104
Belton, V.; Stewart, T. 2002. Multiple criteria decision analysis: an integrated approach. Dordrecht: Kluwer Academic Publishers. http://dx.doi.org/10.1007/9781-4615-1495-4

Benefield, J.; Pyles, M.; Gleason, A. 2011. Sale price, marketing time, and limited service listings: the influence of home value and market conditions, Journal of Real Estate Research 33(4): 531-563.

Bin, O. 2004. A prediction comparison of housing sales prices by parametric versus semi-parametric regressions, Journal of Housing Economics 13(1): 68-84. http://dx.doi.org/10.1016/j.jhe.2004.01.001

Bourassa, S; Cantoni, E.; Hoesli, M. 2010. Predicting house prices with spatial dependence: a comparison of alternative methods, Journal of Real Estate Research 32(2): 139-160.

Cheng, P.; Lin, Z.; Liu, Y. 2011. Property delisting, housing cycle and pricing bias, Journal of Housing Economics 20(2): 152-157. http://dx.doi.org/10.1016/j. jhe.2011.02.002

Clark, T. 1995. Rents and prices of housing across areas of the United States: a cross-section examination of the present value model, Regional Science and Urban Economics 25(2): 237-247. http://dx.doi. org/10.1016/0166-0462(94)02066-P

Diaz, J. III.; Hansz, J. 2001. The use of reference points in valuation judgment, Journal of Property Research 18(2): 141-148.

http://dx.doi.org/10.1080/09599910110039897

Doignon, J. 1984. Threshold representations of multiple semiorders, SIAM Journal of Algebraic Discrete Methods 8(1): 77-84. http://dx.doi.org/10.1137/0608005

Dorsey, R.; Hua, H.; Mayer, W.; Wang, H. 2010. Hedonic versus repeat-sales housing price indexes for measuring the recent boom-bust cycle, Journal of Housing Economics 19(2): 75-93. http://dx.doi.org/10.1016/j. jhe.2010.04.001

Downs, D.; Güner, Z. 2013. Commercial real estate, information production and market activity, Journal of Real Estate Finance and Economics 46(2): 282-298. http://dx.doi.org/10.1007/s11146-011-9348-6

Downs, D.; Güner, Z. 2012. Information producers and valuation: evidence from real estate markets, Journal of Real Estate Finance and Economics 44(1/2): 167183. http://dx.doi.org/10.1007/s11146-010-9294-8

Dyer, R.; Forman, E. 1992. Group decision support with the analytic hierarchy process, Decision Support Systems 8(2): 99-124. http://dx.doi.org/10.1016/01679236(92)90003-8

Eden, C. 2004. Analyzing cognitive maps to help structure issues or problems, European Journal of $\mathrm{Op}$ erational Research 159(3): 673-686. http://dx.doi. org/10.1016/S0377-2217(03)00431-4

Eden, C.; Ackermann, F. 2001a. Group decision and negotiation in strategy making, Group Decision and Negotiation 10(2): 119-140. http://dx.doi. org/10.1023/A:1008710816126

Eden, C.; Ackermann, F. 2001b. SODA - the principles, in J. Rosenhead, J. Mingers, (Eds.). Rational analysis for a problematic world revisited: problem structuring methods for complexity, uncertainty and conflict. $2^{\text {nd }}$ ed. Chichester: John Wiley \& Sons, 21-41. 
Eden, C.; Banville, C. 2003. Construction d'une vision stratégique au moyen de la cartographie cognitive assisté par ordinateur, in P. Cossette, (Eds.). Cartes cognitives et organisations. Les Éditions de L'ADREG, France.

Englund, P.; Quigley, J.; Redfearn, C. 1998. Improved price indexes for real estate: measuring the course of Swedish housing prices, Journal of Urban Economics 44(2): 171-196. http://dx.doi.org/10.1006/ juec.1997.2062

Ettema, D. 2011. A multi-agent model of urban processes: modelling relocation processes and price setting in housing markets, Computers, Environment and Urban Systems 35(1): 1-11.

http://dx.doi.org/10.1016/j.compenvurbsys.2010.06.005

Ferreira, F.; Jalali, M.; Meidutè-Kavaliauskienè, I.; Viana, B. 2015. A metacognitive decision making based-approach to bank customer loyalty measurement and management, Technological and Economic Development of Economy 21(2): 280-300. http://dx.doi.org/10.3846/20294913.2014.981764

Ferreira, F.; Santos, S.; Rodrigues, P. 2011a. Adding value to bank branch performance evaluation using cognitive maps and MCDA: a case study, Journal of the Operational Research Society 62(7): 1320-1333. http://dx.doi.org/10.1057/jors.2010.111

Ferreira, F.; Santos, S.; Rodrigues, P. 2011b. From traditional operational research to multiple criteria decision analysis: basic ideas on an evolving field, Problems and Perspectives in Management 9(3): 114-121.

Ferreira, F.; Santos, S.; Rodrigues, P.; Spahr, R. 2014a. Evaluating retail banking service quality and convenience with MCDA techniques: a case study at the bank branch level, Journal of Business Economics and Management 15(1): 1-21. http://dx.doi.org/10.38 46/16111699.2012.673504

Ferreira, F.; Santos, S.; Rodrigues, P.; Spahr, R. 2014b. How to create indices for bank branch financial performance measurement using MCDA techniques: an illustrative example, Journal of Business Economics and Management 15(4): 708-728.

http://dx.doi.org/10.3846/16111699.2012.701230

Ferreira, F.; Spahr, R.; Santos, S.; Rodrigues, P. 2012. A multiple criteria framework to evaluate bank branch potential attractiveness, International Journal of Strategic Property Management 16(3): 254-276. http://dx.doi.org/10.3846/1648715X.2012.707629

Filipe, M.; Ferreira, F.; Santos, S. 2015. A multiple criteria information system for pedagogical evaluation and professional development of teachers, Journal of the Operational Research Society, 66: 1769-1782. http://dx.doi.org/10.1057/jors.2014.129

Fischer, D. 2003. Multi-criteria analysis of ranking preferences on residential traits, in Proceedings of the 10th European Real Estate Society Conference, 10-13 June 2003, Helsinki, Finland.

http://dx.doi.org/10.15396/eres2003_154

González, M.; Formoso, C. 1995. Estimativa de modelos de preços hedônicos para locação residencial em Porto Alegre, Revista Produção 5(1): 65-77.

http://dx.doi.org/10.1590/s0103-65131995000100004

Gouriéroux, C.; Laferrère, A. 2009. Managing hedonic housing price indexes: the French experience,
Journal of Housing Economics 18(3): 206-213. http://dx.doi.org/10.1016/j.jhe.2009.07.012

Guo, H.; Li, H.; Shen, Q; Wang, Y.; Li, Y. 2007. Real estate confidence index based on Web GIS and SPSS WebAPP, International Journal of Project Management 25(2): 171-177. http://dx.doi.org/10.1016/j.ijproman.2006.09.015

Hjalmarsson, E.; Hjalmarsson, R. 2009. Efficiency in housing markets: which home buyers know how to discount?, Journal of Banking \& Finance 33(11): 2150-2163. http://dx.doi.org/10.1016/j.jbankfin.2009.05.014

Hongyu, L.; Yue, S. 2005. Housing prices and general economic conditions: an analysis of Chinese new dwelling market, Tsinghua Science and Technology 10(3): 334-343. http://dx.doi.org/10.1016/S10070214(05)70078-X

Jacquet-Lagrèze, E.; Siskos, Y. 2001. Preference disaggregation: 20 years of MCDA experience, European Journal of Operational Research 130(2): 233-245. http://dx.doi.org/10.1016/S0377-2217(00)00035-7

Junior, H. 2008. Multicriteria approach to data envelopment analysis, Pesquisa Operacional 28(2): 231-242.

Keeney, R. 1992. Value-focused thinking: a path to creative decisionmaking. Harvard: Harvard University Press.

Malienė, V. 2011. Specialised property valuation: multiple criteria decision analysis, Journal of Retail \& Leisure Property 9(5): 443-450. http://dx.doi.org/10.1057/rlp.2011.7

Malienė, V.; Deveikis, S.; Kirsten, L.; Malys, N. 2010. Commercial leisure property valuation: a comparison of the case studies in UK and Lithuania, International Journal of Strategic Property Management 14(1): 35-48. http://dx.doi.org/10.3846/ijspm.2010.04

Nowak, M. 2011. Interactive multicriteria decision aiding under risk: methods and applications, Journal of Business Economics and Management 12(1): 69-91. http://dx.doi.org/10.3846/16111699.2011.555366

Osland, L. 2010. An application of spatial econometrics in relation to hedonic house price modeling, Journal of Real Estate Research 32(3): 289-320.

Pace, K.; Barry, R.; Gilley, O.; Sirmans, C. 2000. A method for spatial-temporal forecasting with an application to real estate prices, International Journal of Forecasting 16(2): 229-246. http://dx.doi.org/10.1016/ S0169-2070(99)00047-3

Peterson, S.; Flanagan, A. 2009. Neural network hedonic pricing models in mass real estate appraisals, Journal of Real Estate Research 31(2): 147-164.

Quigley, J. 1995. A simple hybrid model for estimating real estate price indexes, Journal of Housing Economics 4(1): 1-12. http://dx.doi.org/10.1006/ jhec.1995.1001

Quigley, J. 2006. Real estate portfolio allocation: the European consumers' perspective, Journal of Housing Economics 15(3): 169-188. http://dx.doi.org/10.1016/j. jhe.2006.09.003

Santos, S.; Belton, V.; Howick, S. 2002. Adding value to performance measurement by using systems dynamics and multicriteria analysis, International Journal of Operations \& Production Management 22(11): 12461272. http://dx.doi.org/10.1108/01443570210450284 
Schulz, R.; Werwatz, A. 2011. Is there an equilibrating relationship between house prices and replacement cost? Empirical evidence from Berlin, Journal of Urban Economics 69(3): 288-302. http://dx.doi.org/10.1016/j.jue.2010.12.003

Shin, W-J.; Saginor, J.; Van Zandt, S. 2011. Evaluating subdivision characteristics on single-family housing value using hierarchical linear modeling, Journal of Real Estate Research 33(3): 317-348.

Smith, B. 2006. The impact of tax increment finance districts on localized real estate: evidence from Chicago's multifamily markets, Journal of Housing Economics 15(1): 21-37. http://dx.doi.org/10.1016/j. jhe.2006.02.003

Suedel, B.; Kim, J.; Banks, C. 2009. Comparison of the direct scoring method and multi-criteria decision analysis for dredged material management decision making [online]. ERDC - Engineer Research and Development Center. Available at: http://el.erdc.usace. army.mil/elpubs/pdf/doerr13.pdf [accessed February 2015].

Wolverton, M.; Gallimore, P. 1999. Client feedback and the role of the appraiser, Journal of Real Estate Research 18(3): 415-431.

Wu, H. 2012. Constructing a strategy map for banking institutions with key performance indicators of the balanced scorecard, Evaluation and Program Planning 35(3): 303-320.

http://dx.doi.org/10.1016/j.evalprogplan.2011.11.009

Wu, J.; Gyourko, J.; Deng, Y. 2011. Evaluating conditions in major Chinese housing markets, Regional Science and Urban Economics 42(3): 531-543. http://dx.doi.org/10.1016/j.regsciurbeco.2011.03.003

Yan, Y.; Wei, X.; Hui, B.; Yang, S.; Wen, Z.; Hong, Y.; Shou-yang, W. 2007. Method for housing price forecasting based on TEI@I methodology, Systems Engineering - Theory \& Practice 27(7): 1-9.

Zavadskas, E.; Ginevičius, R.; Kaklauskas, A.; Banaitis, A. 2005. Analysis and modeling of the Lithuanian real estate sector, Journal of Business Economics and Management 6(3): 135-143.

Zhou, Y.; Haurin, D. 2010. On the determinants of house value volatility, Journal of Real Estate Research 32(4): 377-395. 